\title{
Performance of Hard X-ray Zone Plates at the Advanced Photon Source
}

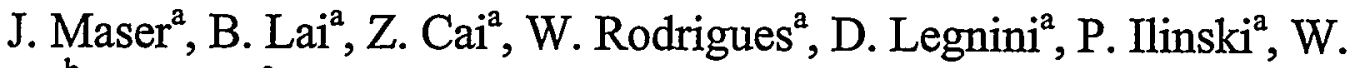 \\ Yun $^{b}$, Z. Chen ${ }^{c}$, A.A.Krasnoperova ${ }^{c}$, Y. Vladimirsky ${ }^{c}$, F. Cerrina ${ }^{c}$, E. Di$$
\text { Fabrizio }^{\mathrm{d}} \text {, M. Gentili }{ }^{\mathrm{d}}
$$ \\ ${ }^{a}$ Advanced Photon Source, Argonne National Laboratory, Argonne, IL 60439 \\ ${ }^{b}$ Advanced Light Source, Lawrence Berkeley National Laboratory, Berkeley, CA 94720 \\ ${ }^{c}$ Center for X-ray Lithography, University of Wisconsin, Madison, WI 53706 \\ ${ }^{d}$ Istituto di Elettronica dello Stato Solido, Consiglio Nazionale delle Ricerche (CNR), \\ Italy-00156

\begin{abstract}
Fresnel zone plates have been highly successful as focusing and imaging optics for soft $\mathrm{X}$-ray microscopes and microprobes. More recently, with the advent of third-generation high-energy storage rings, zone plates for the hard $\mathrm{x}$-ray regime have been put to use as well. The performance of zone plates manufactured using a combination of electron-beam lithography and $\mathrm{x}$-ray lithography is described.
\end{abstract}

\section{INTRODUCTION}

Fresnel zone plates have proven to be superior optical systems for $x$-ray microscopy in the soft $\mathrm{x}$-ray region [1,2]. With the advent of third-generation hard $\mathrm{x}$-ray synchrotrons, microfocusing experiments at high spatial resolution have become feasible in the intermediate to hard $\mathrm{x}$-ray region as well. We use Fresnel zone plates as focusing elements for our hard $\mathrm{x}$-ray microprobes at the sector 2 undulator beamline at the Advanced Photon Source for X-ray energies between $6 \mathrm{keV}$ and $30 \mathrm{keV} \mathrm{[3]} \mathrm{and}$ will report on performance measurements.

With increasing photon energy, the interaction of $x$-rays with matter decreases, and the material thickness required to obtain the phase shift and/or absorption necessary to obtain significant diffraction efficiency increases even if heavier elements are chosen. The typical thickness $t$ ranges from hundreds of nanometers in the soft $x$-ray range to micrometers in the multi-keV range to tens of micrometers for harder energies (Fig. 1). On the other hand, the numerical aperture, and thereby the resolution limit of the zone plate, are determined by the outermost zone width $d r_{n}$. The aspect ratio $t / d_{n}$ therefore increases significantly with increasing energy, making the manufacture of zone plates with a small outermost zone width more difficult. With most manufacturing techniques, high resolution can therefore be achieved only at the cost of reducing the thickness of the zone plate, thereby limiting the usable energy range and/or reducing the diffraction efficiency. 


\section{DISCLAIMER}

This report was prepared as an account of work sponsored by an agency of the United States Government. Neither the United States Government nor any agency thereof, nor any of their employees, make any warranty, express or implied, or assumes any legal liability or responsibility for the accuracy, completeness, or usefulness of any information, apparatus, product, or process disclosed, or represents that its use would not infringe privately owned rights. Reference herein to any specific commercial product, process, or service by trade name, trademark, manufacturer, or otherwise does not necessarily constitute or imply its endorsement, recommendation, or favoring by the United States Government or any agency thereof. The views and opinions of authors expressed herein do not necessarily state or reflect those of the United States Government or any agency thereof. 


\section{DISCLAIMER}

Portions of this document may be illegible in electronic image products. Images are produced from the best available original document. 
We show data obtained for zone plates with an outermost zone width of $0.1 \mu \mathrm{m}$ at energies around $8 \mathrm{keV}$, from stacked zone plates with an outermost zone width of 0.25 $\mu \mathrm{m}$ at energies of 12 and $40 \mathrm{keV}$, and of blazed zone plates with an outermost period of $0.5 \mu \mathrm{m}$.

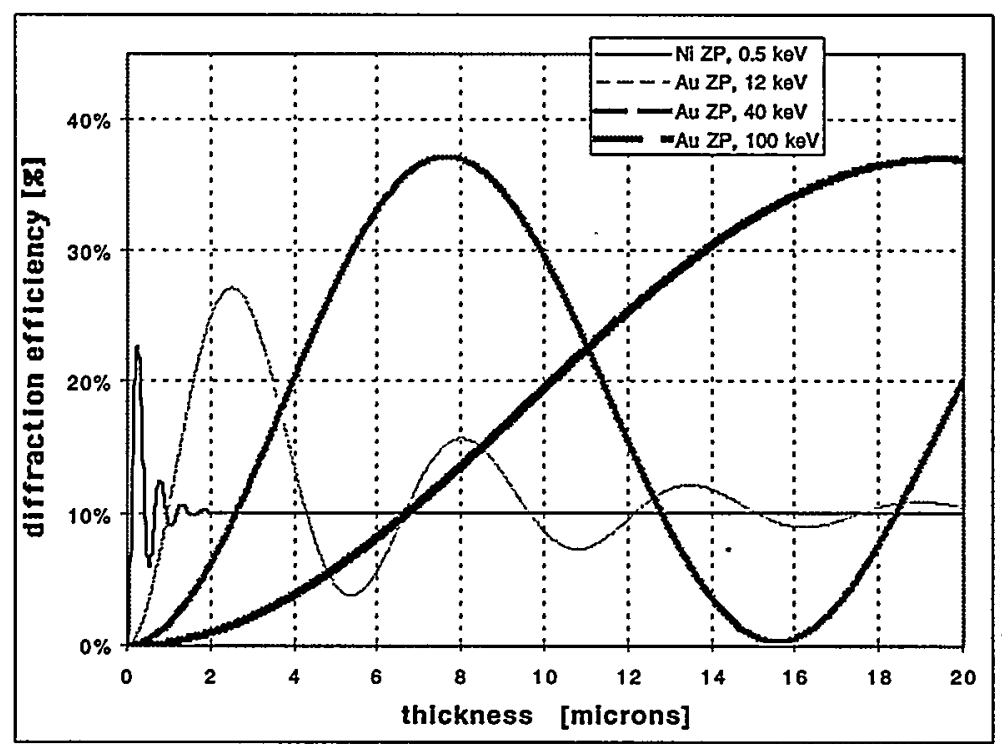

FIGURE 1 Calculated diffraction efficiency (from [4]) for zone plates with rectangular grating profile at $\mathrm{X}$-ray energies between $0.5 \mathrm{keV}$ and $100 \mathrm{keV}$.

\section{RESOLUTION OF MULTI-KEV ZONE PLATES}

Fig. 2 shows resolution tests performed at a photon energy of $8 \mathrm{keV}$. We used a gold zone plate with an outermost zone width of $0.1 \mu \mathrm{m}$ and a diameter of $145 \mu \mathrm{m}$, corresponding to a focal length of $10 \mathrm{~cm}$ at $8 \mathrm{keV}$. The resolution was determined by scanning a knife edge with a $300 \AA$ thick layer of $\mathrm{Cr}$ through the focal spot and collecting $\mathrm{Cr} \mathrm{K}_{\alpha}$ fluorescence radiation with an energy dispersive detector (Fig. 2). We performed vertical scans, thus taking advantage of the small vertical particle beam source size (approx. $52 \mu \mathrm{m}$ at 1\% coupling). The zone plate was located $72 \mathrm{~m}$ from the source, yielding a geometrical demagnification of 1:720 in the first diffraction order. Convolution of the demagnified image of the source of $72 \mathrm{~nm}$ FWHM with the diffraction-limited spot size of $122 \mathrm{~nm}$ yields an expected spot size of $142 \mathrm{~nm}$ in the vertical direction. From the knife edge scan, we obtain a obtain a FWHM spot size of $150 \mathrm{~nm}$, well in agreement with our expectation.

To obtain a smaller spot size, we also investigated focusing the third diffraction order of the zone plate. As previously, we placed a Cr knife edge into the third-order focal plane and scanned it through the focal spot. In the third diffraction order, the numerical aperture is three times larger than in the first order, and a spot size of $47 \mathrm{~nm}$ would be expected. We measured a spot size of just below $90 \mathrm{~nm}$. We attribute the 
difference mostly to mechanical vibrations, coupled with long dwell times at reduced third order flux, and a smaller signal/noise ratio due to the absence of a central stop.

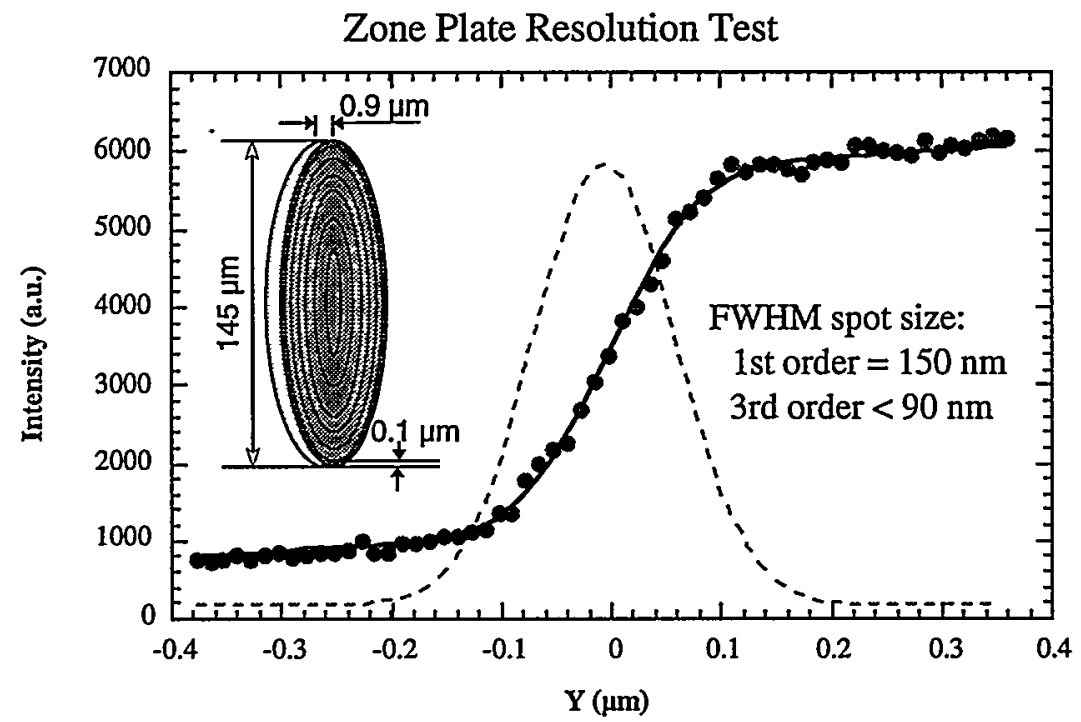

FIGURE 2 Measured resolution of a zone plate with an outermost zone width of $0.1 \mu \mathrm{m}$.

Measurements were performed for the first as well as for the third diffraction order of the zone plate. A Cr knife edge was scanned vertically through the focal spot.

\section{BLAZED ZONE PLATES}

One of the factors that determines the diffraction efficiency is the zone profile. A pure phase zone plate with rectangular profile can achieve a diffraction efficiency of $41 \%$. By changing the zone profile, the distribution of energy into the different diffraction orders is changed. By approaching an idealized, parabolic profile, diffraction efficiencies approaching $100 \%$ can be achieved.

A good approach to the ideal zone profile is a step profile. A zone plate with three electroplated gold levels, representing a 4-step profile, a thickness of $2.5 \mu \mathrm{m}$ and an outermost period of $0.5 \mu \mathrm{m}$ was manufactured using x-ray lithography (Fig. 3$)[5,6]$. We measured a diffraction efficiency of $44 \%$ at a photon energy of $8 \mathrm{keV}$ in the first diffraction order. The flux density in the zero order is reduced, yielding a flux density ratio between focus and background of $>1000$. 

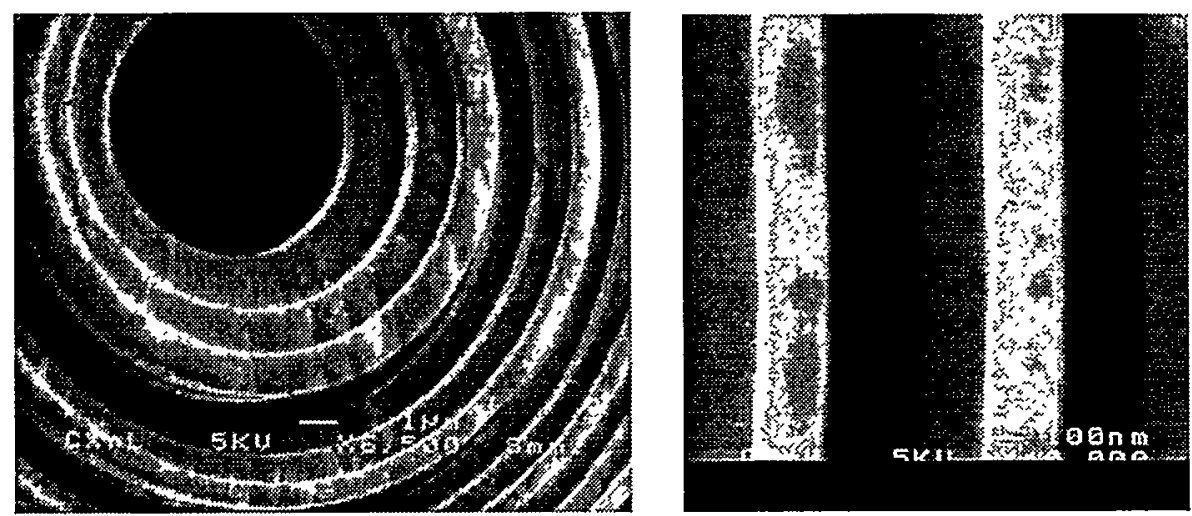

FIGURE 3 Gold zone plate with stepped profile consisting of 4 steps. The left image shows the center, the right image the outermost zones. The outermost period is $0.5 \mu \mathrm{m}$.

\section{NEAR-FIELD STACKING OF ZONE PLATES}

A relatively simple way of multiplying the zone plate thickness to increase the efficiency and use zone plates at higher energies is by stacking several identical zone plates on one axis. To achieve constructive interference, all zone plates have to be aligned laterally to better than a zone width (typically $1 / 3 \mathrm{dr}_{n}$ ), and longitudinally such that they stay within near-field diffraction, within a proximity $\mathrm{p}$ of each other:

$$
p<\mathrm{dr}_{\mathrm{n}}^{2} / \lambda \quad \text { (i.e. } p<<\text { depth of focus). }
$$

For example, for zone plates with an outermost zone width of $200 \mathrm{~nm}$, the required minimum proximity $p$ for the stack of zone plates is $1.3 \mathrm{~mm}$ at $40 \mathrm{keV}$ and $3.3 \mathrm{~mm}$ at $100 \mathrm{keV}$. Accordingly, a stack of three zone plates, aligned to within $0.9 \mathrm{~mm}$, and with an individual thickness of $1.5 \mu \mathrm{m}$ would achieve a diffraction efficiency of $25 \%$ at $40 \mathrm{keV}$. A stack of six such zone plates would achieve a focusing efficiency of $15 \%$ at a photon energy of $100 \mathrm{keV}$ and could have a focal length between $50 \mathrm{~cm}$ and 100 $\mathrm{cm}$.

We have used stacked zone plates at different energies. Fig. 4 shows alignment of two stacked zone plates with an thickness of $3 \mu \mathrm{m}$ and an outermost zone width of 250 $\mu \mathrm{m}$ at a photon energy of $40 \mathrm{keV}$ [3]. We measured a diffraction efficiency of $25 \%$. The flux density of the aligned stack is approximately $60 \%$ larger than the flux density achieved with a the single zone plate, demonstrating the effect of multiplying the thickness. Alignment of the two zone plates is achieved by maximizing the fringe spacing of the Moire patterns resulting from interference between the two zone plates. The Moire patterns are observed in transmission on a scintillator screen. Alignment is usually accomplished in few minutes.

Fig. 5 shows stacking of two zone plates with a thickness of $1.5 \mu \mathrm{m}$ and an outermost zone width of $0.25 \mu \mathrm{m}$ at an energy of $12 \mathrm{keV}$. An improved stage that allows stacking of up to three zone plates was used, and an increase of $47 \%$ in the focused flux is observed. The aligned stack was stable over a 12 hour testing period 
and has allowed us to use stacked zone plates as standard optical elements in microfocusing experiments. We are currently commissioning a stage that allows alignment of two zone plates with small outermost zone width in close proximity.
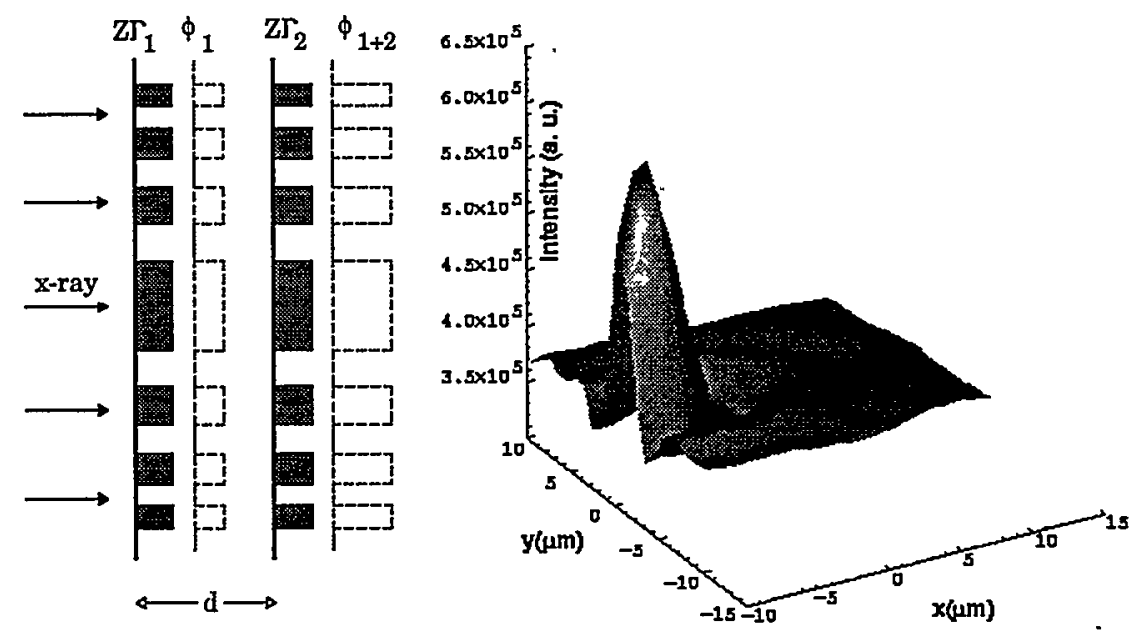

Figure 4. Near-field stacking of two gold zone plates with thickness $3 \mu \mathrm{m}$ at a photon energy of 40 $\mathrm{keV}$. Measurement of the interference pattern is obtained by scanning one zone plate with respect to the other one. An increase of focused flux by $60 \%$ is achieved when both zone plates are aligned (cf. fig. 1).

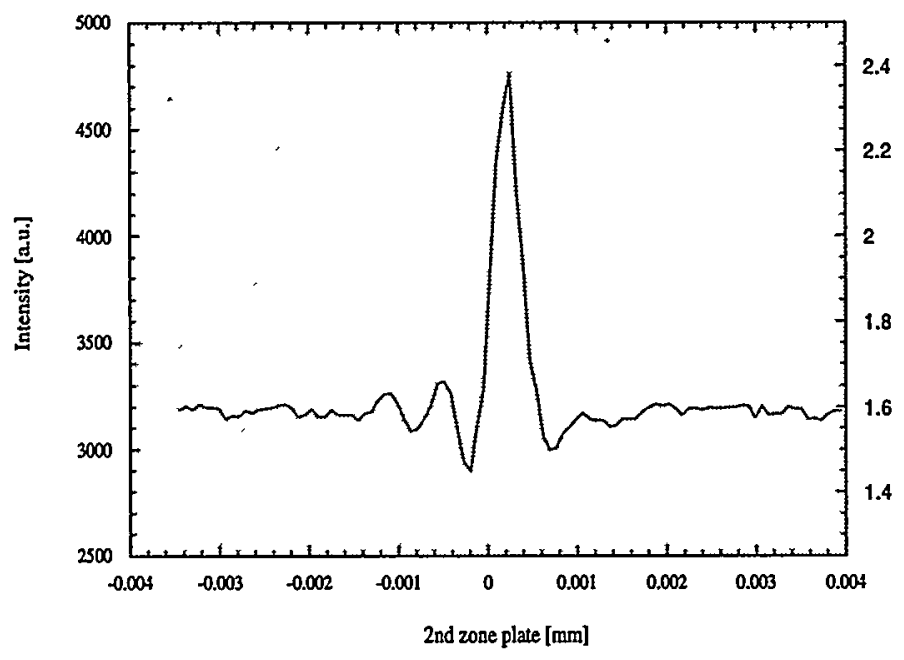

Figure 5. Near-field stacking of two gold zone plates with a thickness of $1.5 \mu \mathrm{m}$ at a photon energy of $12 \mathrm{keV}$. A $47 \%$ increase of efficiency is obtained when the two zone plates are aligned (cf. fig. 1).

\section{CONCLUSIONS}

We have discussed enhancements of our capabilities in using zone plates in the multi-keV and hard $\mathrm{x}$-ray range. 
1) We use zone plates with focal lengths between $5 \mathrm{~cm}$ and $3 \mathrm{~m}$ (at $8 \mathrm{keV}$ ) and outermost zone widths of $100 \mathrm{~nm}-250 \mathrm{~nm}$ for a wide range of applications. We obtain a focused flux of $5^{*} 10^{7}-10^{10} \mathrm{hv} / \mathrm{s}$, and achieve a flux density gain of $10^{4}-10^{5}$.

2) For standard operation between $4 \mathrm{keV}$ and $12 \mathrm{keV}$, zone plates with an outermost zone width of $100 \mathrm{~nm}$ and a focal length between $5 \mathrm{~cm}(4 \mathrm{keV})$ and $15 \mathrm{~cm}$ $(12 \mathrm{keV})$ are used. A resolution of $150 \mathrm{~nm}$ in first order is routinely achieved. A resolution of $<90 \mathrm{~nm}$ in third order at $8 \mathrm{keV}$ has been measured

3) We measured a diffraction efficiency of $44 \%$ for blazed zone plates with an outermost period of $0.5 \mu \mathrm{m}$ and demonstrated a reduction of background from the zero diffraction order.

4) Near-field stacking of two zone plates has been demonstrated to increase the diffraction efficiency by $50 \%-60 \%$ for energies between $12 \mathrm{keV}-40 \mathrm{keV}$.

\section{ACKNOWLEDGEMENTS}

This work is supported by the U. S. Department of Energy, Office of Basic Energy Sciences, under contract W-31-109-ENG-38.

\section{REFERENCES}

1. See papers in "X-ray Microscopy and Spectromicroscopy", edited by Thieme, J., Schmahl, G., Rudolph, D. E. Umbach, E., Springer, Berlin, 1998.

2. Kirz, J., Jacbsen, C., Howells, M., Quart. Rev. Biophys. 28, 33-130 (1995).

3. Lai, B., Yun, W.,. Maser, J.,. Cai, Z., Rodrigues, W., Legnini, D., Chen, Z.,. Krasnoperova, A., Vladimirsky, Y., Cerrina, F., Di Fabrizio, E., Gentili, M, SPIE Proc. 3449, 133 (1998).

4. Kirz, J., J. Opt. Soc. Am. 64, $301-309$ (1974).

5. DiFabrizio, E., Gentili, M., Grella, L., Baciocchi, M., Krasnoperova, A., Cerrina, F., Yun, W., Lai, B., Gluskin, E., J. Vac. Sci. Téchnol. B 12(0), 3979-95 (1994).

6. DiFabrizio, E., this volume. 


\section{Sector 2 Beamline Tasks}

7 December 1999

1. Safety-related and beam-critical tasks

Clean up, organize lead storage area (3-BM)

Clean up, organize cabling behind racks (2-BM-B)

Install AC wiring for new Step-Pak transformer (2-ID-B)

2. Shutdown tasks (Dec 99 - Jan 00)

Reorganize all cabling (2-BM-A)

Install second set of signal (16), HV (4) cables (2-BM-B)

Replace dead motor controller/driver units (2-BM-B)

Mount 2-ID Status Board on aisle partition (2-ID-B,C,D,E)

Reorganize all cabling (2-ID-A)

Tie in M4 (2), M2C, M2B, M3B TCs to EPS (2-ID-A)

Tie in remaining ion gauges (GB2, GB10) to EPS (2-ID-B)

Install second cable tray at upstream/inboard corner (2-ID-B)

Reorganize existing (13), install new (11) motor cables in mini-hutch (2-ID-B)

Build, install (4) miniature motor current limiting boxes (2-ID-B)

Tie in remaining ion pump (GC11) to EPS (2-ID-C)

Install He flow swiches for Be windows, tie in to EPS (2-BM-B, 2-ID-D)

Re-route CCD cooling lines (2-ID-D)

Install 8 new motor cables (2-ID-D)

Align splitter crystal (2-ID-E)

Install motor current limiting box (2-ID-E)

Install, test 3rd group of 8 motors with patch panel (2-ID-E)

Tie in Love controllers (beamsplitter, Kohzu) to EPS (2-ID-E)

Prep hutch (drill floor, install cable trays, etc.) for rebuild (2-ID-E)

Move Kohzu if 4 weeks lead time available (2-ID-E)

Label all Love controllers (2-BM-A, 2-ID-A,B,C,E)

Verify all electrical circuits, labeling (throughout Sector)

Connect specified ports to .100 (throughout Sector)

3. Mid-run tasks (Dec 99)

Install guard around SGM joy-stick and grating masks (2-ID-B)

Install cabling for 13-element detector (2-ID-D)

Install 13-element detector system (2-ID-D)

Implement smart EPS/ID gap limits (2-ID)

Install PC, software for PI CCD (2-ID-D) 
Install X-terminal, rearrange equipment (2-ID-D)

Install 8 new motor channels (2-ID-D)

Install remote shutter control interfaces (2-BM-A,B)

Diagnose vibration in Y4 cooling lines (2-ID-A)

Copy, archive all experiment logs (2-BM, 2-ID-C, 2-ID-D)

4. Shutdown tasks (Apr-May 00)

Install, align DMM (2-BM-A)

Tie in remaining ion gauges (DMM) to EPS (2-BM-A/B)

Install, align focusing crystal in Kohzu (2-BM-A)

Install, align L5-82 masks (2-ID-A)

Major station rebuild (2-ID-E)

Validate EPS systems (throughout Sector)

5. On-going and long-term tasks

Update, web-ize Sector policy and procedure documentation

Management Plan, off-normal contacts

Experiment Safety

Controls

Vacuum

Utilities

LN2 dewar refill schedule

EPS

TSW system maintenance schedule

PSS

Beamline startup/shutdown/changeover checklists

Microscopy and sample preparation facilities

Experiment data archival schedule

Component restocking schedule (431B-020, expt. floor)

Install general purpose DIO boards for IOCs (throughout Sector)

Implement, test EPS/EPICS communication (throughout Sector)

Design, install soft EPS panels (2-BM-A/B, then throughout Sector)

Design, install distributed LN2 system (2-ID-D/E, fill station at 2-ID-A) 